Neu, R. L. and Gardner, L. I. (1972). Three families with abnormal inherited chromosomes: $2 q^{+}$mat, $t\left(\mathrm{Cp}^{+} ; 13 \mathrm{q}^{-}\right)$mat, and $\mathrm{t}\left(3(?)^{-}\right.$; $\left.5 \mathrm{q}^{+}\right)$pat. Annales de Génétique, 15, 19-24.

Paris Conference (1971). Standardization in human cytogenetics. Birth Defects: Original Article Series, 8, pt. 7, 1972. National Foundation-March of Dimes, New York.

Rethoré, M. O., Lejeune, J., Carpentier, S., Prieur, M., Dutrillaux B., Seringe, P., Rossier, A., and Job, J. C. (1972). Trisomie pour 1a partie distale du bras court du chromosome 3 chez trois germains. Premier exemple d'insertion chromosomique: ins $(7 ; 3)$ (q31;p21 26). Annales de Génétique, 15, 159-165.

Seabright, M. (1972). The use of proteolytic enzymes for the mapping of structural rearrangements in the chromosomes of man. Chromosoma, 36, 204-210.

Taillemite, J.-L., Baheux-Morlier, G., Cathelineau, L., and Roux, C. (1973). Maladie du cri du chat associé à un remaniement chromosomique complexe chez un jumeau dizygote. Annales de Génétique, 16, 127-130.

Taysi, K., Bobrow, M., Balci, S., Madan, K., Atasu, M., and Say, B. (1973). Duplication/deficiency product of a pericentric inversion in man: a cause of D1 trisomy syndrome. Fournal of Pediatrics, $82(2), 263-268$.

Therkelsen, A. J., Hultén, M., Jonasson, J., Lindsten, J., Christensen, N. C., and Iversen, T. (1973). Presumptive direct insertion within chromosome 2 in man. Annals of Human Genetics, 36, 367-374.

\section{Bloom's syndrome: a probable new case with cytogenetic findings}

\author{
Summary. A 19-year-old Jordanian \\ girl, born to first-cousin parents, has most \\ features of Bloom's syndrome but is tall \\ and has secondary amenorrhoea. Blood \\ and skin cultures revealed a normal dip- \\ loid female complement but about one- \\ quarter of the cells show chromosome or \\ chromatid gaps, breaks, and rearrange- \\ ments. These abnormalities were \\ localized after trypsin banding and have \\ been found non-randomly distributed \\ along the chromosomes.
}

\section{Case report}

The propositus is the third child of first-cousin parents. It is reported that she was not unusually small at birth. The family is Jordanian, of Moslem religion. There is no family history of a similar condition. Height is 164 $\mathrm{cm}$, weight $36 \mathrm{~kg}$, a head circumference of $49 \mathrm{~cm}$ - that is below the 1st centile for Palestinian Arab women and Indians (Meredith, 1971). She looks younger than 19. She has extensive scarring of the face and a rash, with both erythema and telangiectasis, which affects the cheeks, nose, eyelids, lips, and forehead. There was ectopia of the left lower lid with synechia of the exposed conjuntiva with keratinization. The dorsal skin of forearms and digits is atrophic, and there is slight atrophy of the

Received 8 November 1974.
TABLE

ANALYSIS OF THE DIFFERENT TYPES OF ABERRATIONS

\begin{tabular}{l|c|c|c}
\hline & \multicolumn{3}{|c|}{ Culture Time } \\
\cline { 2 - 4 } & $48 \mathrm{~h}$. & $72 \mathrm{~h}$. & Total \\
\hline No. of cells & 203 & 302 & 505 \\
\% of cells with abnormalities & 26.5 & 21.1 & 23.3 \\
Aberrations per cell & 0.31 & 0.258 & 0.279 \\
\hline Chromatid gaps & 8 & 13 & 21 \\
Isogaps & 4 & 10 & 14 \\
Chromatid breaks & 8 & 2 & 10 \\
Chromosome breaks & 31 & 40 & 71 \\
Quadriradials & 2 & 1 & 3 \\
Dicentrics & 4 & 1 & 5 \\
Rings & - & 1 & 1 \\
Translocations & 1 & 2 & 3 \\
Acentric fragments & 5 & 6 & 11 \\
Chromosome duplications & - & 2 & 2 \\
'Cross-configurations' & 6 & 4 & 10 \\
& & & \\
\hline
\end{tabular}

skin of the upper back. The skin changes appeared at 3 months and are related to sun sensitivity. There are also a few small pigmented cafe-au-lait patches and a very large lesion of irregular contour $(20 \times 20 \mathrm{~cm})$ with lentigines in it. Breast development is poor and pubic hair scanty. She had had two or three periods since the age of 16 and there was no response to stimulation of the ovaries. The only radiographical abnormality is a short right thumb, found also in her father.

The alpha-feto-protein and haemoglobin levels are within the normal range, but the IgA and IgM levels are below normal as described in Bloom's syndrome by Landau et al (1966) and Rauh and Saukup (1968).

\section{Cytogenetic studies}

Lymphocyte chromosome analysis of three different samples taken at monthly intervals, each grown for 48 and $72 \mathrm{~h}$, gave almost similar results, which have therefore been pooled (Table). Among 505 well-spread trypsin-banded metaphases $23 \%$ were abnormal. Aberrations were mostly of the chromosome type: chromosomal aberrations and chromatic aberrations were seen in a ratio of approximately $3: 1$. There were rings, dicentrics, translocations, and quadriradials (Figure). In seven of 11 instances the exchanges were between homologues and the break points were symmetrical; only three of these are quadriradials. Ten figures looking like symmetrical primary constriction overlaps of pairs of chromosomes with peculiar stretching out of the constriction/overlap region were seen. These cross-configurations differ from quadriradials as no breaks could be seen.

All the 125 localizable break-points of these structural events, including breaks and gaps are non-random: the centromeric region and telomeric region are especially involved. They show, respectively, $34 \%$ and $20 \%$ of the break-points. 


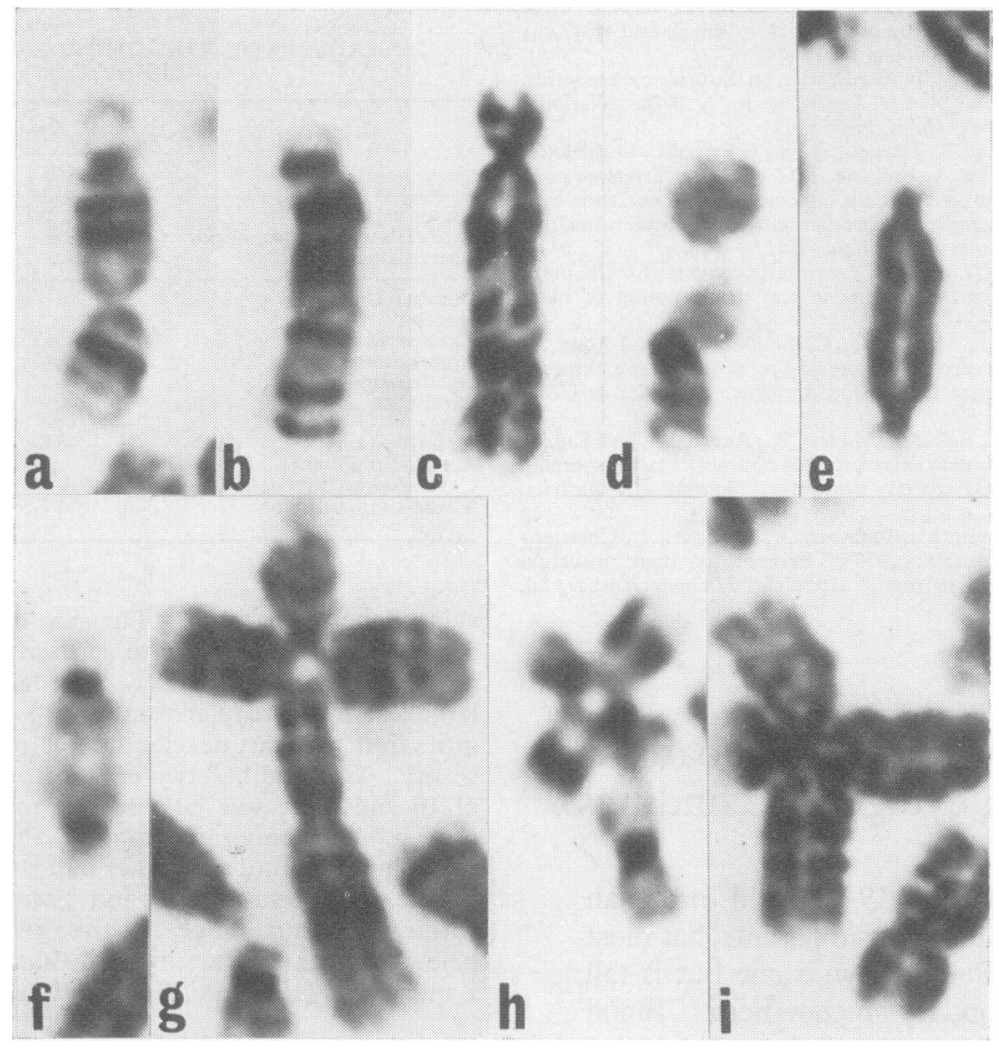

FIGURE. a: Isochromatid gap; b: centromeric chromosome break; c: translocation; d: ring chromosome; $e$ and $\mathbf{f}$ : symmetrical dicentrics; $\mathbf{g}$ : asymmetrical quadriradial; $\mathbf{h}$ : symmetrical quadriradial; i: cross-configuration.

Localization apart, the small sample makes it difficult to assess whether there is randomness in respect to the different pairs of the set. In contrast with the findings in Fanconi's anaemia by Koskull and Aula (1973) and in radiologically induced breakages (Seabright, 1973), the $\mathrm{X}$ chromosome displays no important discrepancy between the observed and the expected number of break-points (nine observed break-points when 6.21 were expected). Skin fibroblast cultures show an increase frequency of chromatin bridges and lagging fragments at anaphase as well as the presence of micronuclei.

\section{Conclusions}

The propositus shows four out of five main features of Bloom's syndrome (German, 1969). She has telangiectatic erythema with atrophy, is sun sensitive, is born from related parents, and appears to show chromosome abnormalities similar to those described by German (1973). The areas of skin pigmentation, and the minor anomaly of the thumb have been reported in Bloom's syndrome. The original description of the syndrome by Bloom (1954) included dwarfism and low birth weight as an important feature of the disease, but our patient was alleged to be of normal size at birth and is comparatively tall. However, her father is $185 \mathrm{~cm}$ and her mother $175 \mathrm{~cm}$ in height.

Nine males (four of Jewish origin and five nonJewish) have been reported to present some genetical defects (undescended testes, urethral stricture and meatal narrowing, hypospadias, testicular atrophy or hypoplasia); the only two adult women with Bloom's syndrome reported had normal sexual development. The fact that phenotypically to some extent, and ethnically, our patient is somewhat unusual may be taken to suggest the possibility that in Bloom's syndrome, as in many other genetic disorders, there is genetic heterogeneity. 
We thank the Department of Health and Social Security and the Spastics Society, for general finiancial help.

\section{A. Bourgeois, * M. H. Calverley, $†$} L. Forman, $\ddagger$ and P. E. PolanI*

\section{REFERENCES}

Bloom, D. (1954). Congenital telangiectatic erythema resembling lupus erythematosus in dwarfs. American fournal of Diseases of Children, 88, 754-758.

German, J. (1969). Bloom's syndrome. I. Genetical and clinical observations in the first twenty-seven patients. American fournal of Human Genetics, 21, 196-227.

German, J. (1973). Oncogenic implications of chromosomal instability. Hospital Practice, 8, 93-104.

Koskull, H. von, and Aula, P. (1973). Non random distribution of chromosome breaks in Fancon's anemia. Cytogenetics and Cell Genetics, 12, 423-435.

Landau, J. W., Sasaki, M. S., Newcomer, V. D., and Norman, A (1966). Bloom's syndrome. Archives of Dermatology, 94, 687694

Meredith, H. V. (1971). Human head circumference from birth to early adulthood: racial, regional and sex comparisons. Growth, 35, 233-245.

Rauh, J. L. and Soukup, S. W. (1968). Bloom's syndrome. American fournal of Diseases of Children, 116, 409-413.

Seabright, M. (1973). High resolution studies on the pattern of induced exchanges in the human karyotype. Chromosoma, 40, 333346.

* Paediatric Research Unit, Cameron House, Guy's Hospital Medical School, London SE1.

† 99 Harley Street, London, W1.

$\ddagger 22$ Harley House, London NW 1 .

\section{Trisomy $4 \mathrm{q} 32 \rightarrow 4 \mathrm{qter}$ due to a maternal $4 / 21$ translocation}

Summary. The case is described of a malformed girl with partial trisomy for a segment of the long arm of chromosome $(4 \mathrm{q} 32 \rightarrow$ qter $)$ due to an unfavourable segregation of a maternal reciprocal translocation $\mathrm{t}(4 ; 21) \quad(\mathrm{q} 32 \mathrm{q} 22)$. The clinical comparison between the child and patients previously described by other authors does not suggest the existence of a syndrome associated with trisomy $4 \mathrm{q}+$.

To date there are only four clinical descriptions of partial trisomy for the long arm of chromosome 4, the chromosome being identified by autoradiography (Surana and Conen, 1972) or by banding techniques (Francke, 1972; Chapelle et al, 1973; Schrott et al, 1974). Recently another two cases of

Received 21 November 1974. trisomy $4 \mathrm{q}+$ in a family with a translocation $\mathrm{t}(4 \mathrm{q} ; 18 \mathrm{q})$ have been published (Knörr-Gärtner et al, 1974) but no report of the clinical picture was included. We would like to describe a patient who presents a peculiar phenotype and who is affected by trisomy $4 \mathrm{q}+$ as a consequence of a familial translocation $\mathrm{t}(4 \mathrm{q} ; 21 \mathrm{q})$.

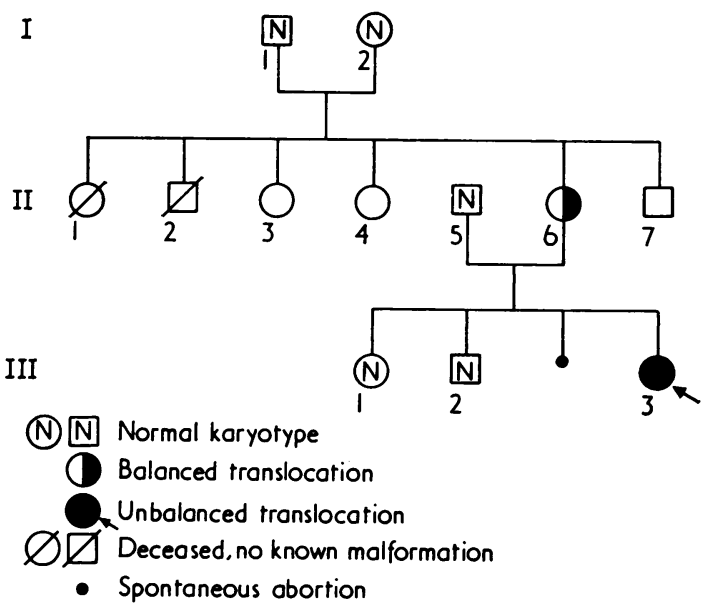

Fig. 1. Pedigree.

\section{Case report}

The proposita, born 25 March 1966, was the result of a fourth pregnancy of a mother aged 40 and a father aged 43. The previous three pregnancies (Fig. 1) resulted in the birth of a normal healthy female, now aged 21 , a healthy male, now aged 13, and a spontaneous abortion which occurred during the second month of pregnancy in 1965. The patient was born at term after an uneventful pregnancy apart from slight recurrent vaginal bleeding. Birth weight was $1950 \mathrm{~g}$ (below the 10th centile); length and head circumference were not registered. The neonatal period was uneventful except for problems of nutrition, growth, and psychomotor development. At 6 months her weight was $3500 \mathrm{~g}$ and head circumference $36 \mathrm{~cm}$; at 13 months she was able to sit, weight was $5800 \mathrm{~g}$, and head circumference $39 \mathrm{~cm}$. She took her first steps at 26 months; weight was $8700 \mathrm{~g}$ and head circumference $43 \mathrm{~cm}$. She is now $8 \frac{1}{2}$ years and weighs $15 \mathrm{~kg}$ and is $112 \mathrm{~cm}$ tall with a head circumference of 45 $\mathrm{cm}$. She does not speak and her only expressions are guttural sounds and hand gestures. Her posture and coordination are equivalent to that of a child of 2 years (Fig. 2), while her language and social growth are below this level. Discrete, generalized muscular hypertonia is present and both deep and superficial reflexes are increased. The head is small. Facies are narrow and consist of prominent frontal bossing, low hairline, small and hollowed eyes, depressed bridge of the nose which shows a large bottom and flat top, large philtrum, and 